\title{
Correction to: Is emotion recognition the only problem in ADHD? Effects of pharmacotherapy on face and emotion recognition in children with ADHD
}

\author{
Esra Demirci ${ }^{1} \cdot$ Ayten Erdogan ${ }^{2}$
}

Published online: 21 December 2017

(c) Springer-Verlag GmbH Austria, part of Springer Nature 2017

\section{Correction to: ADHD Atten Def Hyp Disord (2016) 8:197-204 \\ https://doi.org/10.1007/s12402-016-0201-x}

The author would like to correct the error in the publication of the original article. The corrected details are given below for your reading.

First sentence of the "Ethics statement" section should read as:

The study was approved by Erciyes University Medical Faculty's Ethics Committee.

The original article can be found online at https://doi. org/10.1007/s12402-016-0201-x.

Esra Demirci

esra_z_d_r@hotmail.com

1 Department of Child and Adolescent Psychiatry, Erciyes University, School of Medicine, 38039 Kayseri, Turkey

2 Department of Psychology, Beykent University, Faculties of Science and Literature, Istanbul, Turkey 